\title{
Dielectric Properties of Biomass/Biochar Mixtures at Microwave Frequencies
}

\author{
Candice Ellison ${ }^{1}$, Murat Sean McKeown ${ }^{2}$, Samir Trabelsi ${ }^{3}$ and Dorin Boldor ${ }^{1, *}$ \\ 1 Biological and Agricultural Engineering, Louisiana State University, 149 E. B. Doran, Baton Rouge, LA 70803, \\ USA; celli27@lsu.edu \\ 2 College of Engineering, University of Georgia, 597 D. W. Brooks Dr., Athens, GA 30602, USA; \\ mckeown@uga.edu \\ 3 U. S. Department of Agriculture, Agricultural Research Service, Russell Research Center, \\ 950 College Station Rd., Athens, GA 30605, USA; samir.trabelsi@ars.usda.gov \\ * Correspondence: dboldor@agcenter.lsu.edu; Tel.: +1-225-578-7762
}

Academic Editor: Mejdi Jeguirim

Received: 23 February 2017; Accepted: 4 April 2017; Published: 9 April 2017

\begin{abstract}
Material dielectric properties are important for understanding their response to microwaves. Carbonaceous materials are considered good microwave absorbers and can be mixed with dry biomasses, which are otherwise low-loss materials, to improve the heating efficiency of biomass feedstocks. In this study, dielectric properties of pulverized biomass and biochar mixtures are presented from $0.5 \mathrm{GHz}$ to $20 \mathrm{GHz}$ at room temperature. An open-ended coaxial-line dielectric probe and vector network analyzer were used to measure dielectric constant and dielectric loss factor. Results show a quadratic increase of dielectric constant and dielectric loss with increasing biochar content. In measurements on biochar, a strong dielectric relaxation is observed at $8 \mathrm{GHz}$ as indicated by a peak in dielectric loss factor at that frequency. Biochar is found to be a good microwave absorber and mixtures of biomass and biochar can be utilized to increase microwave heating rates for high temperature microwave processing of biomass feedstocks. These data can be utilized for design, scale-up and simulation of microwave heating processes of biomass, biochar, and their mixtures.
\end{abstract}

Keywords: biochar; biomass properties; microwave applications; dielectric properties; bioenergy

\section{Introduction}

Biomass resources offer a plentiful, renewable energy alternative to fossil fuels and can reduce $\mathrm{CO}_{2}$ emission due to the potential of net zero emissions [1]. Lignocellulosic biomass materials can be converted to energy-dense products via thermochemical processes (namely pyrolysis and gasification) [2,3]. During these conversion processes, the biomass feedstock is heated to temperatures in the range of $400-700{ }^{\circ} \mathrm{C}$, usually by conventional heating methods, i.e., conduction and convection [4]. In attempts to improve heating efficiency, recent studies have applied dielectric heating to these thermochemical conversion processes [5-7]. Microwave processing has numerous advantages over conventional methods, including no-contact energy transfer, volumetric energy absorption and dissipation, and selective heating in samples composed of two or more materials.

To effectively design microwave reactors for processing biomass feedstocks, an accurate knowledge of the dielectric properties of biomass materials is necessary to evaluate the dielectric response of materials in an applied electric field [8]. Dielectric properties may be determined by the complex relative permittivity expressed by [9]:

$$
\varepsilon^{*}=\varepsilon^{\prime}-i \varepsilon^{\prime \prime}=\varepsilon^{\prime}(1-i \times \tan \delta)
$$


where $\varepsilon^{\prime}$ is the relative dielectric constant, $\varepsilon^{\prime \prime}$ is the relative dielectric loss factor, $i=\sqrt{-1}$, and $\tan \delta$ is the loss tangent $\left(\tan \delta=\varepsilon^{\prime \prime} / \varepsilon^{\prime}\right)$. Dielectric constant and dielectric loss factor are dimensionless entities, which are used to measure the ability of a material to store energy and the ability of a material to dissipate energy as heat, respectively. Molecular mechanisms dictate the polarization of molecules in an applied electric field and in the microwave frequency range, dipole rotation and ionic conduction are the dominant mechanisms of molecular polarization [8]. Dielectric properties of a material are dependent on many factors such as measurement frequency, material atomic and molecular composition, and physical characteristics [10]. For materials composed of at least two components, dielectric properties are function of the properties of the bulk material such as bulk density, moisture content, and temperature [11].

Dielectric properties of a variety of lignocellulosic biomasses including woody biomass [11-15], grassy biomass [16-18], oil palm [19], corn stover [20], and pulp mill sludge [21] have been presented in the literature. Due to the low dielectric loss of most lignocellulosic biomasses, these materials alone, especially if dry, require a lot of energy to reach high temperatures by dielectric heating if not aided by a microwave absorbing material $[22,23]$. To reach the high temperatures required by thermochemical conversion processes, a microwave absorbing material, characterized by high dielectric loss, can be added to biomass feedstocks $[6,24,25]$. When a high-loss material is added to a low-loss material, the dielectric loss of the overall mixture is increased, resulting in greater heat generation in the bulk material.

Carbonaceous materials, including carbon black, carbon nanotubes, carbon fibers, graphene, activated carbon, $\mathrm{SiC}$, and pyrolytic biochar have been recognized as good microwave absorbers for their potential to convert microwave energy into thermal energy $[6,24,26,27]$. In this study, biochar was investigated for its microwave absorbing potential since it is a low cost and convenient feedstock additive that is readily available as a byproduct of thermochemical conversion processes. When a mixture of biomass and biochar is irradiated with microwaves, the biochar particles selectively heat, followed by heat transfer to adjacent biomass particles by conduction and by convection. Few studies have investigated the dielectric properties of pyrolytic biochars [17,19,27,28]. Motasemi et al. measured the dielectric properties of hay, switchgrass, and corn stover during pyrolysis $[16,17,20]$. Low dielectric properties were observed from room temperature to $450{ }^{\circ} \mathrm{C}$ during pyrolysis, but a sudden increase in dielectric properties was observed as the feedstock was heated from 450 to $700{ }^{\circ} \mathrm{C}$ when the biochar had been formed. Salema et al. [19] and Tripathi et al. [28] measured the dielectric properties of biochar derived from pyrolysis of oil palm shell.

While dielectric properties of biomass and biochar have been investigated separately, dielectric properties of biomass and biochar mixtures have never been measured to our knowledge. Dielectric properties of mixtures of biomass and biochar at room temperature are important for the efficient use of microwaves to initiate dielectric heating for thermochemical conversion processes. This study aims to fill this knowledge gap by characterizing the dielectric properties of biomass/biochar mixtures for four different biomass feedstocks readily available in Louisiana and southeastern United States: energy cane bagasse, pine sawdust (Pinus sp.), live oak (Quercus sp.), and Chinese tallow tree wood (Triadica sebifera (L.)). Each of the biomasses chosen for this study can be sourced from various biomass waste streams, making them viable feedstocks for thermochemical conversion processes. Pine sawdust is a forestry residue from logging operations and a waste from milling processes. Energy cane bagasse is a byproduct of the sugar industry, a residual lignocellulosic material after the juices are pressed from the cane. Chinese tallow tree is an invasive species whose population is controlled to protect native species and wetlands in southeastern United States. Live oak is an urban waste from tree pruning and other tree maintenance services. These lignocellulosic biomass wastes have great potential as feedstocks for biofuel production processes due to their low cost, but the dielectric properties when mixed with biochar as absorbers need to be investigated in order to effectively design microwave-based processes and equipment. 


\section{Materials and Methods}

\subsection{Biochar Preparation}

The biochar used in these experiments was obtained from biomass pyrolysis of various feedstocks (mostly pine sawdust). Ground biomass was packed into a stainless-steel tube and heated via induction heating to $400-600{ }^{\circ} \mathrm{C}$ under a continuous flow of nitrogen gas. After complete pyrolysis, the tube was cooled to room temperature and the biochar was collected from the tube. The biochar was ground and sieved to obtain particle sizes less than $5 \mu \mathrm{m}$.

\subsection{Biomass Sample Preparation}

Energy cane, pine wood, live oak, and Chinese tallow tree samples were obtained by grinding wood chips or shavings using a wood chipper and laboratory blender, and sieved to less than $5 \mu \mathrm{m}$ particle size. For each biomass, the following biochar mixtures were prepared: 0 wt \%, 25 wt \%, $50 \mathrm{wt} \%, 75 \mathrm{wt} \%, 100 \mathrm{wt} \%$ biochar. The moisture contents of each sample were measured on a wet basis using a standardized oven drying method (ASTM E871-82) and are presented in Table 1. Bulk density at the time of measurement was determined gravimetrically by dividing the weight of the sample by the volume of the sample measurement cup (Table 1).

Table 1. Moisture content (MC) and density of each of the biomass/biochar samples measured.

\begin{tabular}{|c|c|c|c|c|c|c|c|c|}
\hline \multirow{2}{*}{$\begin{array}{l}\text { Biochar } \\
\text { (\% wt) }\end{array}$} & \multicolumn{2}{|c|}{ Energy Cane } & \multicolumn{2}{|c|}{ Sawdust } & \multicolumn{2}{|c|}{ Live Oak } & \multicolumn{2}{|c|}{ Chinese Tallow Tree } \\
\hline & $\begin{array}{c}\text { MC (\% wet } \\
\text { basis) }\end{array}$ & $\begin{array}{l}\text { Density } \\
\left(\mathrm{g} / \mathrm{cm}^{3}\right)\end{array}$ & $\begin{array}{c}\text { MC (\% wet } \\
\text { basis) }\end{array}$ & $\begin{array}{l}\text { Density } \\
\left(\mathrm{g} / \mathrm{cm}^{3}\right)\end{array}$ & $\begin{array}{c}\text { MC (\% wet } \\
\text { basis) }\end{array}$ & $\begin{array}{l}\text { Density } \\
\left(\mathrm{g} / \mathrm{cm}^{3}\right)\end{array}$ & $\begin{array}{c}\text { MC (\% wet } \\
\text { basis) }\end{array}$ & $\begin{array}{l}\text { Density } \\
\left(\mathrm{g} / \mathrm{cm}^{3}\right)\end{array}$ \\
\hline 25 & $9.32 \pm 0.20$ & 0.25 & $9.68 \pm 0.06$ & 0.30 & $10.87 \pm 1.00$ & 0.41 & $9.00 \pm 0.17$ & 0.37 \\
\hline 50 & $7.93 \pm 0.00$ & 0.29 & $8.05 \pm 0.02$ & 0.37 & $8.57 \pm 0.30$ & 0.46 & $7.30 \pm 0.22$ & 0.41 \\
\hline 75 & $6.50 \pm 0.01$ & 0.32 & $6.57 \pm 0.12$ & 0.45 & $6.84 \pm 0.05$ & 0.49 & $6.63 \pm 0.08$ & 0.48 \\
\hline
\end{tabular}

\subsection{Measurement Procedure}

For this study, the open-ended coaxial-line dielectric probe method was utilized, despite its limitations for measurement of low-loss solid materials [14,29], due to its ease of use and ability to cover a broad range of electromagnetic frequencies. This technique is convenient due to easy sample preparation and small sample size requirement; however, it is sensitive to local inhomogeneities in the test material due to the small measurement region of the probe [30]. If the sample is not homogenous, the resulting measurement is an average value weighted by the intensity of the electric field which is at its highest at the center conductor of the probe tip [31]. Air gaps in the measurement region are another source of error when measuring granular solids [32] and methods to control these errors have been developed and are discussed further [33]. Since the materials being measured in the present study are pulverized to a fine powder consistency, these sources of error can be carefully prevented. Precautions were taken to ensure firm contact of the probe with the sample and to make certain the probe face was presented with a single, smooth, flat surface with gap-free contact. In this study, three to five replicates were measured after agitating and recompressing the sample into the sample holder to verify the consistency of the readings and avoid measurement errors due to sample inhomogeneity.

A schematic of the dielectric measurement setup is shown in Figure 1. The measurement system consisted of an Agilent 85070 high-temperature dielectric probe connected via a coaxial cable to a vector network analyzer (Agilent N5230C PNA-L). The specific sample requirements for the probe are a minimum diameter $>20 \mathrm{~mm}$, a granule size $<0.3 \mathrm{~mm}$, and a minimum sample thickness given by the following equation [31]:

$$
\text { sample thickness }>\frac{20}{\sqrt{\left|\varepsilon^{*}\right|}} \mathrm{mm}
$$


where $\left|\varepsilon^{*}\right|$ is the modulus of the permittivity given by:

$$
\left|\varepsilon^{*}\right|=\sqrt{\left(\varepsilon^{\prime}\right)^{2}+\left(\varepsilon^{\prime \prime}\right)^{2}}
$$

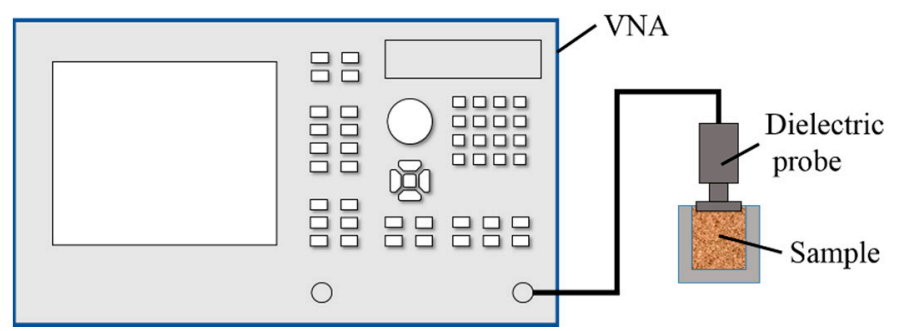

Figure 1. Sample measurement set-up consisting of a vector network analyzer (VNA) and high temperature coaxial-line dielectric probe (Agilent 85070) inserted into sample.

The instrument was calibrated using open air, a short, and distilled water at $25{ }^{\circ} \mathrm{C}$ as reference standards. The dielectric probe was fixed on a stand and the samples firmly pressed into a cylindrical stainless steel cup ( $1 \mathrm{~cm}$ radius, $2 \mathrm{~cm}$ height) by raising an adjustable platform. Measurements consisted of 101-point logarithmic sweep from 0.2 to $20 \mathrm{GHz}$. Dielectric constant and dielectric loss factor readings were acquired for each biomass/biochar mixture. Due to observed issues with this method at low frequencies, the data measured below $0.5 \mathrm{GHz}$ were discarded. The permittivity measurements at $2.45 \mathrm{GHz}$ were obtained by interpolation of dielectric constant and dielectric loss factor values at their respective neighboring frequencies. This frequency was selected as it is the most commonly used frequency in the industrial, scientific, and medical (ISM) radio bands for microwave heating applications. The accuracy of dielectric properties obtained from the probe is specified by the manufacturer as [31]:

$$
\begin{aligned}
\varepsilon^{\prime} & =\varepsilon^{\prime} \pm 0.05\left|\varepsilon^{*}\right| \\
\varepsilon^{\prime \prime} & =\varepsilon^{\prime \prime} \pm 0.05\left|\varepsilon^{*}\right|
\end{aligned}
$$

\section{Results}

In the context of this study, measurements performed at microwave frequencies showed dependence of dielectric constant and dielectric loss factor on frequency, mixture ratio, and biomass type. Figures 2 and 3 depict the frequency dependence of the real $\left(\varepsilon^{\prime}\right)$ and imaginary $\left(\varepsilon^{\prime \prime}\right)$ parts of permittivity, respectively, for each biomass/biochar mixture. Dielectric constant decreases with increasing frequency for all samples over the measured frequency range. This observed monotonic decrease is due to the decrease in polarization of the dielectric material with increasing frequency, as it is described by Torgovnikov [11]. The phase of the charged particles of the dielectric lags behind the phase of the electric field due to polarization relaxation. With increasing frequency, the number of charged particles that are in phase with the electric field decreases, resulting in a decrease in dielectric constant. Percent decreases of dielectric constant from the maximum at $0.5 \mathrm{GHz}$ to the minimum at $20 \mathrm{GHz}$ are denoted in Table 2. Dielectric loss factor increases to a maximum between 8 and $9 \mathrm{GHz}$ for the biomass/biochar mixtures less than or equal to $75 \%$ weight biochar. For the samples with $100 \%$ weight biochar, dielectric loss factor decreases between 0.5 and $2 \mathrm{GHz}$ followed by an increase, which peaks at $8 \mathrm{GHz}$, then decreases from 8 to $20 \mathrm{GHz}$. 


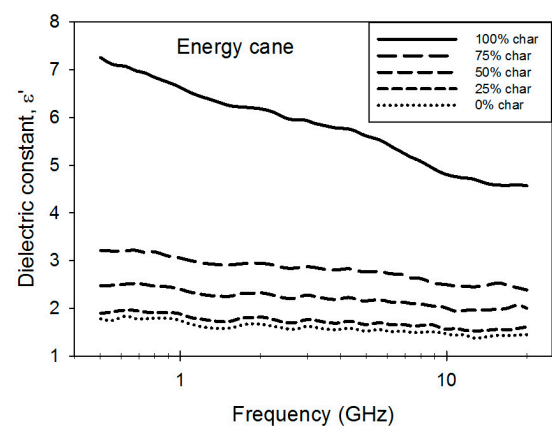

(a)

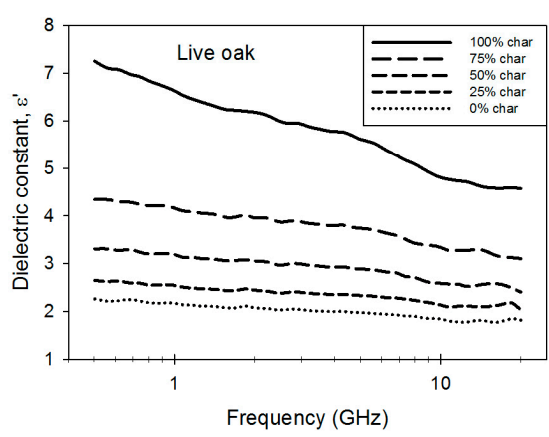

(c)

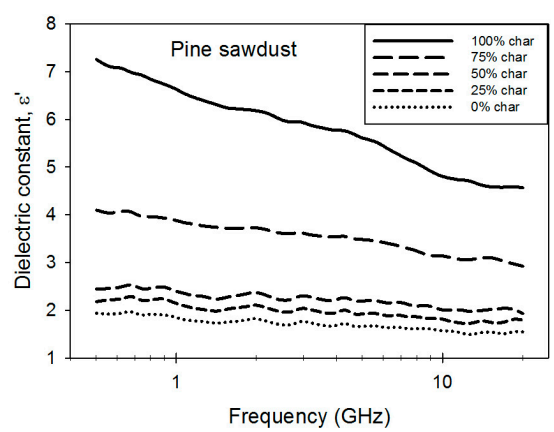

(b)

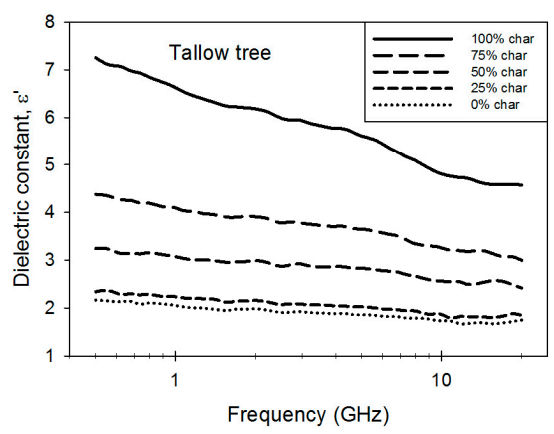

(d)

Figure 2. Measured dielectric constant from 0.5 to $20 \mathrm{GHz}$ of each biomass sample: (a) energy cane bagasse; (b) pine sawdust; (c) live oak; and (d) Chinese tallow tree wood at the indicated biochar contents.

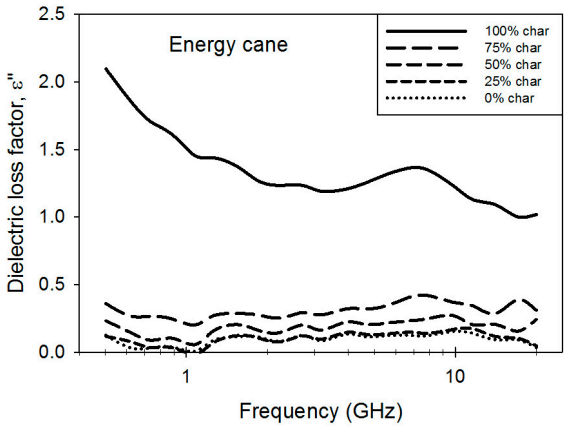

(a)

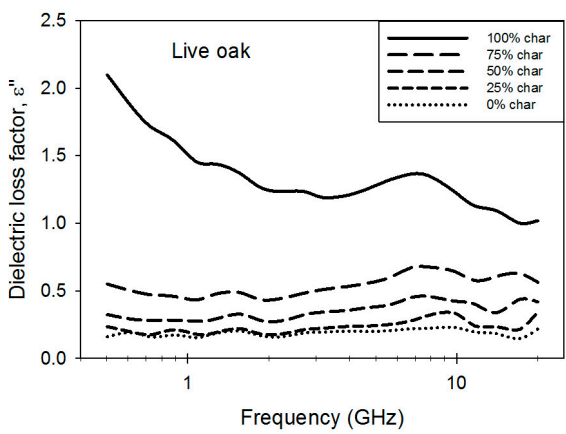

(c)

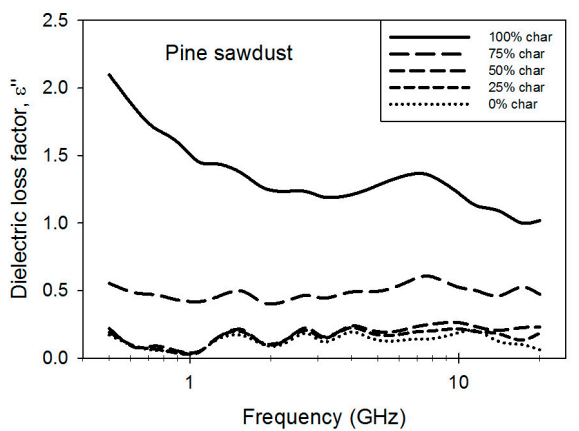

(b)

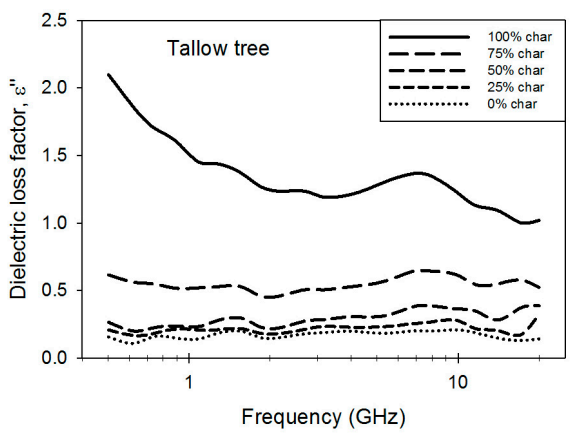

(d)

Figure 3. Measured dielectric loss constant from 0.5 to $20 \mathrm{GHz}$ of each biomass sample: (a) energy cane bagasse; (b) pine sawdust; (c) live oak; and (d) Chinese tallow tree wood) at the indicated biochar contents. 
Table 2. Percent differences (\%) in dielectric constant from 0.5 to $20 \mathrm{GHz}$.

\begin{tabular}{ccccc}
\hline Biochar & Energy Cane & Pine Sawdust & Live Oak & Chinese Tallow Tree \\
\hline 0 & 8.83 & 8.98 & 21.48 & 11.61 \\
25 & 5.06 & 2.35 & 27.04 & 24.37 \\
50 & 11.86 & 7.64 & 30.81 & 28.09 \\
75 & 25.49 & 28.91 & 34.98 & 35.02 \\
100 & 44.41 & 44.41 & 44.41 & 44.41 \\
\hline
\end{tabular}

Dielectric properties are dependent on bulk density of air-particle mixtures [34]. The biochar measured in this study is denser than the biomass materials, thus the measured permittivity values of the various biomass/biochar mixtures partially reflect the effect of density on the apparent permittivity. The observed increase in dielectric properties with increasing biochar content cannot be attributed to the biochar alone since with an increase in biochar, there is also an increase in density. To eliminate the effect of density on dielectric properties, the measured permittivity data of each mixture at its respective density was transformed to the corresponding permittivity value at a mean bulk density by the Landeau and Lifshitz, Looyenga equation [10]:

$$
\varepsilon_{2}^{\prime}=\left[\frac{\varepsilon_{1}^{1 / 3}-1}{\rho_{1}} \rho_{2}+1\right]^{3}
$$

where $\rho$ is bulk density and $\varepsilon$ represents permittivity. The subscripts 1 and 2 denote the original measured parameter and the transformed parameter, respectively.

Figure 4 illustrates the dielectric constant and dielectric loss factor as a function of biochar content and corrected to a mean density $\left(0.32,0.39,0.46\right.$ and $0.43 \mathrm{~g} / \mathrm{cm}^{3}$, for energy cane, pine sawdust, live oak, and Chinese tallow tree, respectively) using Equation (6). For all biomasses measured, the real and imaginary parts of dielectric properties are shown to increase as biochar content increases. Since biochar has a greater dielectric constant than the biomass samples, addition of biochar to the biomass feedstock increases the overall dielectric constant of the bulk material. At $2.45 \mathrm{GHz}$, the average dielectric constant of the raw biomasses and biochars are 2.13 and 4.06, respectively, corresponding to twofold increase. A regression analysis was performed and it was determined that the permittivity of the mixture follow a quadratic function of biochar content. The dependency of permittivity on biochar content can be described by a quadratic function of the form $y=A x^{2}+B x+C$, and the coefficients of the quadratic regression and the regression coefficient are presented in Table 3.

Table 3. Quadratic regression coefficients $\left(y=\mathrm{A} x^{2}+\mathrm{B} x+\mathrm{C}\right)$ for the dependence of dielectric constant $\left(\varepsilon^{\prime}\right)$ and dielectric loss factor $\left(\varepsilon^{\prime \prime}\right)$ on biochar content for each biomass type at $2.45 \mathrm{GHz}$.

\begin{tabular}{ccccc|cccc}
\hline \multirow{2}{*}{ Sample } & \multicolumn{4}{c|}{$\mathcal{\varepsilon}^{\prime}$} & \multicolumn{4}{c}{$\varepsilon^{\prime \prime}$} \\
\cline { 2 - 9 } & $\mathbf{A}$ & $\mathbf{B}$ & $\mathbf{C}$ & $\boldsymbol{R}^{\mathbf{2}}$ & $\mathbf{A}$ & $\mathbf{B}$ & $\mathbf{C}$ & $\boldsymbol{R}^{\mathbf{2}}$ \\
\hline Energy cane & 0.8187 & 0.5373 & 1.9260 & 0.9604 & 1.9732 & -0.9848 & 0.0615 & 0.9429 \\
Pine sawdust & 2.0488 & -0.2974 & 2.1348 & 0.9711 & 1.6801 & -0.6170 & 0.0639 & 0.9914 \\
Live oak & 2.0412 & 0.3712 & 2.3027 & 0.9947 & 1.5136 & -0.5243 & 0.1488 & 0.9767 \\
Tallow tree & 1.5599 & 0.6214 & 2.1689 & 0.9891 & 1.5184 & -0.4990 & 0.1205 & 0.9896 \\
\hline
\end{tabular}




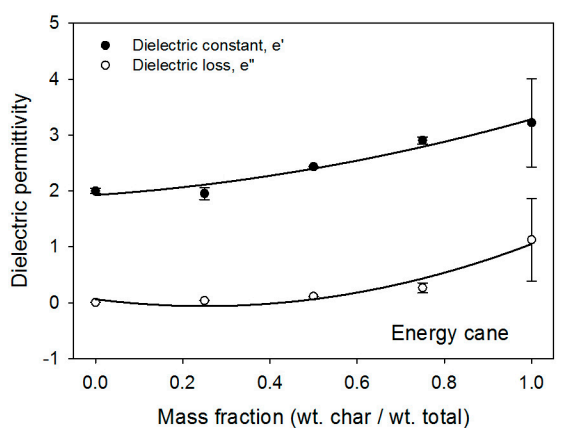

(a)

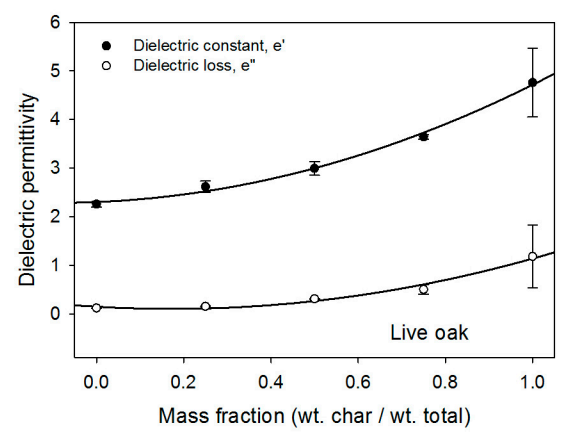

(c)

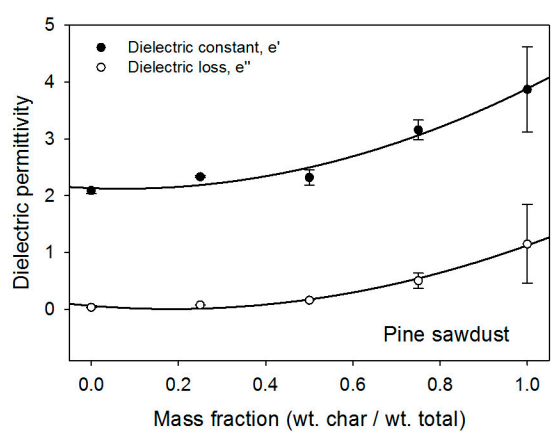

(b)

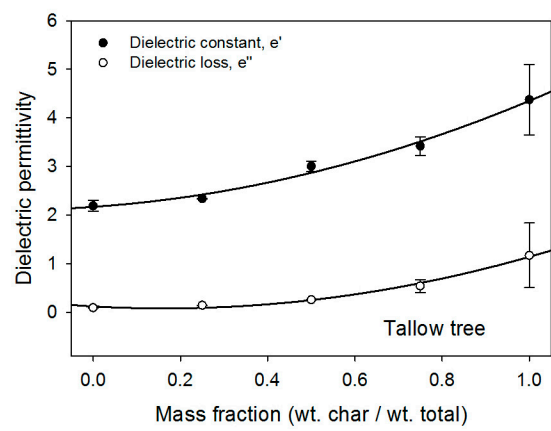

(d)

Figure 4. Dielectric constant and loss factor measurements as a function of biochar content at $2.45 \mathrm{GHz}$ for each biomass: (a) energy cane bagasse; (b) pine sawdust; (c) live oak; and (d) Chinese tallow tree wood). Error bars indicate standard deviations.

Dielectric loss tangent is the ratio of the loss factor to dielectric constant and its dependency on mixture ratio is depicted in Figure 5a. The loss tangent is an indicator of the ability of a material to dissipate electromagnetic energy. A high dielectric loss factor and moderate dielectric constant would be indicative of a good microwave absorber. Similarly, to dielectric constant and dielectric loss, the regression analysis of the loss tangent follows an increasing quadratic trend with increasing biochar content. Penetration depth is defined as the distance into the material at which the power of an incident electric field has decayed by $1 / e$ and is calculated by the following equation (where $\lambda_{0}$ is the frequency of free space):

$$
\delta_{p}=\frac{\lambda_{0}}{2 \pi \sqrt{2 \varepsilon^{\prime}}}\left(\sqrt{1+\left(\varepsilon^{\prime \prime} / \varepsilon^{\prime}\right)^{2}}-1\right)^{-\frac{1}{2}}
$$

Penetration depth was calculated for each biomass/biochar mixture and is shown to decrease quadratically with increasing biochar content (Figure 5b). Knowledge of penetration depth of a material is important for scale-up of microwave heating systems and is useful for designing reactor geometry and dimensions. The coefficients of quadratic regression analysis for loss tangent and penetration depth as functions of biochar content are presented in Table 4. 


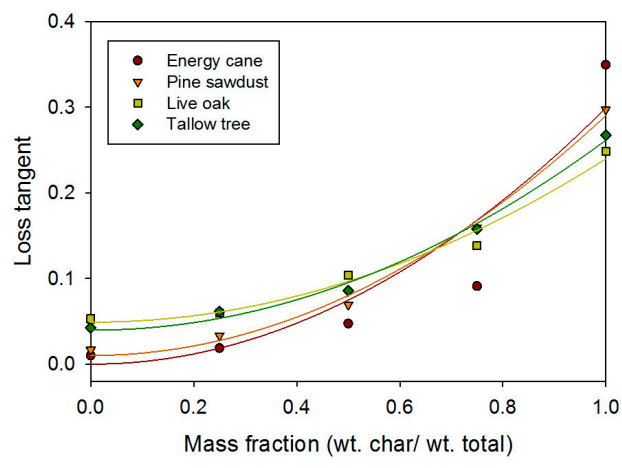

(a)

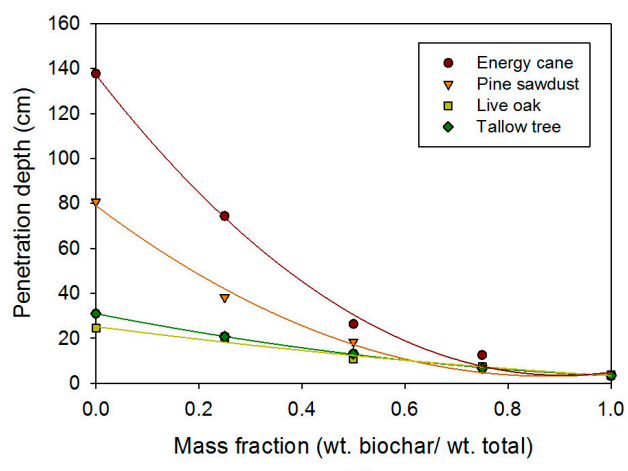

(b)

Figure 5. (a) Dielectric loss factor and (b) penetration depth as a function of biochar content at $2.45 \mathrm{GHz}$ frequencies for each biomass.

Table 4. Quadratic regression coefficients $\left(y=A x^{2}+B x+C\right)$ for loss tan and penetration depth as a function of mass fraction of biochar.

\begin{tabular}{ccccc|cccc}
\hline \multirow{2}{*}{ Sample } & \multicolumn{4}{c|}{ Loss Tan } & \multicolumn{4}{c}{ Penetration Depth } \\
\cline { 2 - 9 } & $\mathbf{A}$ & $\mathbf{B}$ & $\mathbf{C}$ & $\boldsymbol{R}^{\mathbf{2}}$ & $\mathbf{A}$ & $\mathbf{B}$ & $\mathbf{C}$ & $\boldsymbol{R}^{\mathbf{2}}$ \\
\hline Energy cane & 0.2992 & $2.06 \times 10^{-12}$ & $2.06 \times 10^{-12}$ & 0.8827 & 162.4 & -294.7 & 137.3 & 0.9963 \\
Pine sawdust & 0.2802 & $2.52 \times 10^{-12}$ & 0.0101 & 0.9941 & 98.5 & -172.9 & 79.1 & 0.9938 \\
Live oak & 0.1909 & $5.96 \times 10^{-12}$ & 0.0490 & 0.9814 & 7.8 & -29.7 & 25.2 & 0.9789 \\
Tallow tree & 0.2219 & $1.72 \times 10^{-12}$ & 0.0397 & 0.9929 & 17.3 & -44.8 & 31.0 & 0.9996 \\
\hline
\end{tabular}

Comparison of the different biomasses studied show that each biomass exhibits similar, but independent dielectric properties. To illustrate the effect of biomass type on dielectric properties, loss tangent was plotted as a function of frequency for 25\% biochar (Figure 6a) and $75 \%$ biochar (Figure 6b) mixtures. In comparing the measurements on the different biomass at similar biochar contents, it is clear that differences exist between the different materials. By comparing the dielectric properties values of the different biomasses, it is observed that an increased biochar content amplifies the apparent dielectric constant of the mixture.

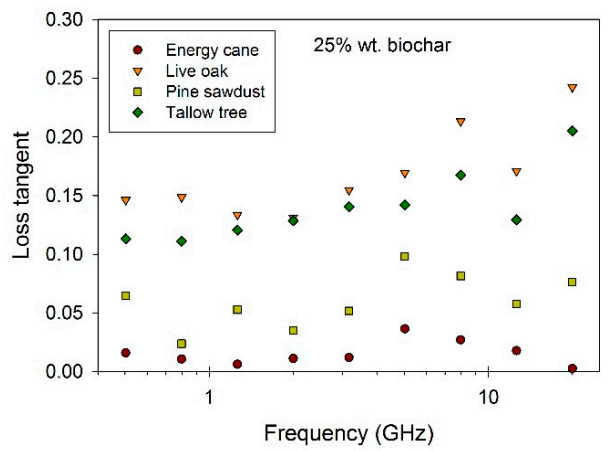

(a)

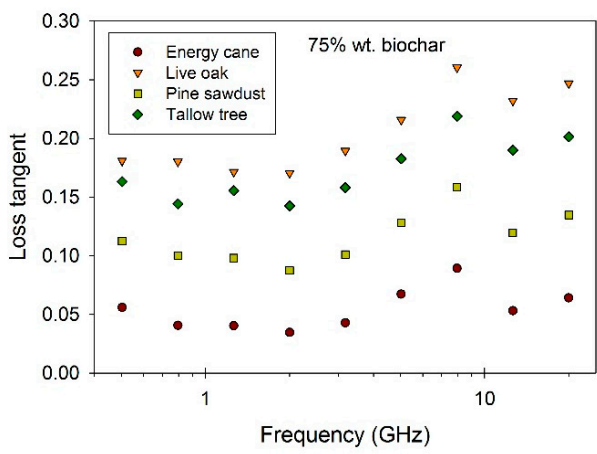

(b)

Figure 6. Effect of biomass type on the loss tangent of two biomass/biochar mixtures: (a) $25 \% \mathrm{wt}$ biochar and (b) $75 \%$ wt biochar.

\section{Discussion}

As seen by the quadratic increase in the loss tangent with increasing biochar, mixtures of biomass and biochar are shown to exhibit greater heat generation ability compared to biomass alone. Carbonaceous solid materials are not heated via dipole polarization like water and other polar liquids, but rather via Maxwell-Wagner-Sillars polarization, or interfacial polarization effects. Carbonaceous 
materials have delocalized $\mathrm{sp}^{2} \pi$-electrons, which move freely within interfacial regions of chars. An applied electric field induces a current in the $\pi$-electrons, which is in phase with the electric field. Over time the $\pi$-electrons become out of phase with the electric field and collisions between electrons generates energy in the form of heat. Thus, the good microwave absorption of biochar reported in literature discussing microwave heating is most likely attributable to the effect of Maxwell-Wagner Sillars polarization [27].

Frequency dependence of biochar is much more pronounced than the frequency dependence of the raw biomasses in this study. An interesting feature of the biochar permittivity data is the dielectric relaxation observed at $8 \mathrm{GHz}$. This relaxation is seen in the mixtures with high biochar content $(75 \%$ and $100 \%$ wt biochar) and it is indicative of a relaxation frequency of the biochar. It is thought that this frequency could correspond to a wavelength that is equal to the mean free path of the free $\pi$-electrons in the biochar interlayers.

A wide range of dielectric properties values have been presented in the literature for carbonaceous materials (Table 5). Dielectric properties of carbonaceous materials are dependent on the origin of the material. Atwater and Wheeler [32] measured the dielectric properties of three different activated carbons and found the permittivity to be dependent on the origin of the material. In addition, measurement techniques and material conditions at the time of measurement should also be noted as a cause of discrepancy between dielectric measurements on similar materials.

Table 5. Dielectric properties of several carbonaceous materials at $2.45 \mathrm{GHz}$.

\begin{tabular}{cccc}
\hline Sample & $\boldsymbol{\varepsilon}^{\prime}$ & $\boldsymbol{\varepsilon}^{\prime \prime}$ & Reference \\
\hline Pyrolysis biochar & 6.00 & 1.22 & This study \\
Oil palm char & 2.83 & 0.23 & {$[19]$} \\
Activated carbon & 5.30 & 0.37 & {$[35]$} \\
Activated carbon & $14-40$ & $4-26$ & {$[36]$} \\
Graphite & 4.20 & 0.11 & {$[35]$} \\
\hline
\end{tabular}

Dielectric properties have been found to increase with moisture content due to the high degree of polarization of water molecules under electromagnetic radiation [21]. In this study, moisture contents ranged from $5.00 \pm 0.01 \%$ for the biochar samples to $11.16 \pm 0.33 \%$ for the average of the biomass samples (Table 1). Despite this decrease in moisture content with increase in biochar, increase of biochar in the mixture increases the dielectric constant and loss factor. If water content was the dominant driving force for variation in dielectric properties, we would expect to see the opposite trend. This confirms that dipole rotation of water molecules is not a dominant mechanism for the dielectric properties of these samples. Permittivity also tends to increase with increasing density [34]. With addition of biochar to biomass, density of the samples increases (Table 1), which could be a cause of the increasing dielectric properties with increasing biochar content. However, as discussed previously, the measured permittivity values were corrected to a medium density using Equation (6) to be able to observe the effect of biochar content without the effect of density.

\section{Conclusions}

The dielectric properties of biomass and biochar mixtures were measured from 0.5 to $20 \mathrm{GHz}$ at room temperature. Results from this study indicate the dependence of permittivity on frequency, biomass type, and mixture ratio. Dielectric properties were found to increase quadratically with increasing biochar content for all biomasses. Dry biomass materials require a considerable amount of microwave energy to reach high processing temperatures by microwave irradiation due to low dielectric properties. Biochar, a byproduct of biomass pyrolysis, was found to be a good microwave absorber and can be used as an additive to biomass feedstocks to increase microwave absorption in the bulk material and accelerate heating rates. The dielectric properties data presented in this study are important for the design, simulation, and scale-up of microwave reactors for high temperature 
microwave processing of biomass materials. Biomass and biochar mixture ratios can be optimized for a given microwave geometry.

Acknowledgments: The authors would like to acknowledge the LSU Agricultural Center, LSU College of Engineering, and LSU Biological and Agricultural Engineering Department for their support of this project. The authors acknowledge NSF CBET (award\# 1437810), and USDA Hatch program (LAB \#94146) and Louisiana Board of Regents (Graduate Fellowship for Candice Ellison under award \#LEQSF(2012-17)-GF-03) for their financial support of this project. A portion of this work was conducted at and using equipment from the USDA Agriculture Research Service lab in Athens, Georgia. The author extends her acknowledgement to Jeff Ortego, McKenna Benbow and Gustavo Aguilar for their technical support. Published with the approval of the Director of the Louisiana Agricultural Experiment Station as manuscript 2017-232-30777.

Author Contributions: Candice Ellison and Dorin Boldor conceived and designed the experiments; Candice Ellison, Murat Sean McKeown and Samir Trabelsi performed the experiments; Candice Ellison analyzed the data; Samir Trabelsi and Dorin Boldor contributed reagents/materials/analysis tools; Candice Ellison wrote the paper.

Conflicts of Interest: The authors declare no conflict of interest.

\section{References}

1. U.S. Department of Energy. 2016 Billion-Ton Report: Advancing Domestic Resources for a Thriving Bioeconomy; Langholtz, M.H., Stokes, B.J., Eaton, L.M., Eds.; Oak Ridge National Laboratory: Oak Ridge, TN, USA, 2016; p. 448.

2. Henkel, C.; Muley, P.D.; Abdollahi, K.K.; Marculescu, C.; Boldor, D. Pyrolysis of energy cane bagasse and invasive Chinese tallow tree (Triadica sebifera L.) biomass in an inductively heated reactor. Energy Convers. Manag. 2016, 109, 175-183. [CrossRef]

3. Bridgwater, A.V. Principles and practice of biomass fast pyrolysis processes for liquids. J. Anal. Appl. Pyrolysis 1999, 51, 3-22. [CrossRef]

4. Bridgwater, A.V. Review of fast pyrolysis of biomass and product upgrading. Biomass Bioenergy 2012, 38, 68-94. [CrossRef]

5. Salema, A.A.; Ani, F.N. Microwave induced pyrolysis of oil palm biomass. Bioresour. Technol. 2011, 102, 3388-3395. [CrossRef]

6. Undri, A.; Abou-Zaid, M.; Briens, C.; Berruti, F.; Rosi, L.; Bartoli, M.; Frediani, M.; Frediani, P. Bio-oil from pyrolysis of wood pellets using a microwave multimode oven and different microwave absorbers. Fuel 2015, 153, 464-482. [CrossRef]

7. Liu, G.; Wright, M.; Zhao, Q.; Brown, R.C. Catalytic fast pyrolysis of duckweed: Effects of pyrolysis parameters and optimization of aromatic production. J. Anal. Appl. Pyrolysis 2015, 112, 29-36. [CrossRef]

8. Thostenson, E.T.; Chou, T.W. Microwave processing: Fundamentals and applications. Compos. Part A Appl. Sci. Manuf. 1999, 30, 1055-1071. [CrossRef]

9. Meredith, R.J. Engineers' Handbook of Industrial Microwave Heating; Institution of Electrical Engineers: London, UK, 1998.

10. Nelson, S.O. Correlating dielectric properties of solids and particulate samples through mixture relationships. Trans. ASAE 1992, 35, 625-629. [CrossRef]

11. Torgovnikov, G.I. Dielectric Properties of Wood and Wood-Based Materials; Springer: Berlin, Germany, 1993.

12. Olmi, R.; Bini, M.; Ignesti, A.; Riminesi, C. Dielectric Properties of Wood from 2 to 3 GHz. J. Microw. Power Electromagn. Energy 2000, 35, 135-143. [CrossRef] [PubMed]

13. Ramasamy, S.; Moghtaderi, B. Dielectric Properties of Typical Australian Wood-Based Biomass Materials at Microwave Frequency. Energy Fuels 2010, 24, 4534-4548. [CrossRef]

14. Paz, A.M.; Trabelsi, S.; Nelson, S.O.; Thorin, E. Measurement of the Dielectric Properties of Sawdust Between 0.5 and 15 GHz. IEEE Trans. Instrum. Meas. 2011, 60, 3384-3390. [CrossRef]

15. McKeown, M.S.; Trabelsi, S.; Tollner, E.W. Effects of temperature and material on sensing moisture content of pelleted biomass through dielectric properties. Biosyst. Eng. 2016, 149, 1-10. [CrossRef]

16. Motasemi, F.; Afzal, M.T.; Salema, A.A. Microwave dielectric characterization of hay during pyrolysis. Ind. Crops Prod. 2014, 61, 492-498. [CrossRef]

17. Motasemi, F.; Afzal, M.T.; Salema, A.A.; Hutcheon, R.M. Microwave dielectric characterization of switchgrass for bioenergy and biofuel. Fuel 2014, 124, 151-157. [CrossRef] 
18. Fennell, L.P.; Boldor, D. Dielectric and Thermal Properties of Sweet Sorghum Biomass. J. Microw. Power Electromagn Energy 2014, 48, 244-260. [CrossRef]

19. Salema, A.A.; Yeow, Y.K.; Ishaque, K.; Ani, F.N.; Afzal, M.T.; Hassan, A. Dielectric properties and microwave heating of oil palm biomass and biochar. Ind. Crops Prod. 2013, 50, 366-374. [CrossRef]

20. Motasemi, F.; Salema, A.A.; Afzal, M.T. Dielectric characterization of corn stover for microwave processing technology. Fuel Process. Technol. 2015, 131, 370-375. [CrossRef]

21. Namazi, A.B.; Allen, D.G.; Jia, C.Q. Probing microwave heating of lignocellulosic biomasses. J. Anal. Appl. Pyrolysis 2015, 112, 121-128. [CrossRef]

22. Zuo, W.; Tian, Y.; Ren, N. The important role of microwave receptors in bio-fuel production by microwave-induced pyrolysis of sewage sludge. Waste Manag. 2011, 31, 1321-1326. [CrossRef] [PubMed]

23. Motasemi, F.; Afzal, M.T. A review on the microwave-assisted pyrolysis technique. Renew. Sustain. Energy Rev. 2013, 28, 317-330. [CrossRef]

24. Shang, H.; Lu, R.R.; Shang, L.; Zhang, W.H. Effect of additives on the microwave-assisted pyrolysis of sawdust. Fuel Process. Technol. 2015, 131, 167-174. [CrossRef]

25. Zhang, S.; Dong, Q.; Zhang, L.; Xiong, Y. High quality syngas production from microwave pyrolysis of rice husk with char-supported metallic catalysts. Bioresour. Technol. 2015, 191, 17-23. [CrossRef] [PubMed]

26. Qin, F.; Brosseau, C. A review and analysis of microwave absorption in polymer composites filled with carbonaceous particles. J. Appl. Phys. 2012, 111, 061301. [CrossRef]

27. Menéndez, J.A.; Arenillas, A.; Fidalgo, B.; Bermúdez, J.M. Review: Microwave heating processes involving carbon materials. Fuel Process. Technol. 2010, 91, 1-8. [CrossRef]

28. Tripathi, M.; Sahu, J.N.; Ganesan, P.; Monash, P.; Dey, T.K. Effect of microwave frequency on dielectric properties of oil palm shell (OPS) and OPS char synthesized by microwave pyrolysis of OPS. J. Anal. Appl. Pyrolysis 2015, 112, 306-312. [CrossRef]

29. McKeown, M.S.; Trabelsi, S.; Tollner, E.; Nelson, S.O. Dielectric spectroscopy measurements for moisture prediction in Vidalia onions. J. Food Eng. 2012, 111, 505-510. [CrossRef]

30. Moreau, J.M.; Aziz, R. Dielectric study of granular media according to the type of measurment device: Coaxial cell or open-ended probe. Meas. Sci. Technol. 1993, 4, 124-129. [CrossRef]

31. Agilent Technologies. Agilent 85070E Dielectric Probe Kit Technical Overview; Agilent Technologies, Inc.: Santa Clara, CA, USA, 2008.

32. Nelson, S.O.; Bartley, P.G. Open-ended coaxial-line permittivity measurements on pulverized materials. IEEE Trans. Instrum. Meas. 1998, 47, 133-137. [CrossRef]

33. Blackham, D.V.; Pollard, R.D. An improved technique for permittivity measurements using a coaxial probe. IEEE Trans. Instrum. Meas. 1997, 46, 1093-1099. [CrossRef]

34. Nelson, S.O. Density-Permittivity Relationships for Powdered and Granular Materials. IEEE Trans. Instrum. Meas. 2005, 54, 2033-2040. [CrossRef]

35. Zhou, F.; Cheng, J.; Liu, J.; Wang, Z.; Zhou, J. Activated carbon and graphite facilitate the upgrading of Indonesian lignite with microwave irradiation for slurryability improvement. Fuel 2016, 170, $39-48$. [CrossRef]

36. Atwater, J.E.; Wheeler, R.R. Complex permittivities and dielectric relaxation of granular activated carbons at microwave frequencies between 0.2 and 26 GHz. Carbon 2003, 41, 1801-1807. [CrossRef]

(C) 2017 by the authors. Licensee MDPI, Basel, Switzerland. This article is an open access article distributed under the terms and conditions of the Creative Commons Attribution (CC BY) license (http:/ / creativecommons.org/licenses/by/4.0/). 